\title{
DEFINIÇÃO TERMINOLÓGICA: DA TEORIA À PRÁTICA
}

Ieda Maria Alves*

RESUMO: Apresentamos, neste trabalho, alguns problemas relativos à elaboração de definições por compreensão em uma língua de especialidade, a Inteligência Artificial. Assim, concluímos que, entre a teoria exposta nas normas terminológicas e o trabalho prático, algumas adequações tornam-se neces-

\section{TERMINOLOGIA E DEFINIÇÃO}

No trabalho terminológico, a definição consiste numa operação muito importante, pois ela é, segundo a Norma ISO 1 087, um "enunciado que descreve um conceito e que permite distingui-lo dos outros conceitos no interior de um sistema de conceitos".

A prática terminográfica mostra que essa operação é, na verdade, bastante complexa. Sager (1990) expõe todos os tipos de definições encontrados em trabalhos de caráter terminológico. Assim, existem definições analíticas, também denominadas por compreensão (termo genérico e características específicas): pneumo- sárias, em função de uma comunicação mais eficaz e do caráter específico de cada língua de especialidade.

UNITERMOS: Terminologia; Língua de especialidade; Definição; Definição por compreensão; Inteligência Artificial.

nia - inflamação do tecido pulmonar; definições sinonímicas: software - programa de computador; definições por paráfrase: brancura - qualidade de branco; definições por síntese (descrevem e identificam relações): frutão - grande árvore da família das sapotáceas, de flores verdes, dispostas em fascículos axilares, cujo fruto, amarelo-esverdeado, é baga globosa de polpa mole, fibrosa, sucosa, comestível, aromática e azeda, com duas sementes ovóides (Ferreira); definições por implicação (uso do termo em um contexto explicativo): diagnóstico - faz-se um diagnóstico quando identificamos certos sintomas como característicos de condições específicas; definições por denota-

* Universidade de São Paulo. 
ção, também designadas por extensão (relacionam exemplos): oceano - o Atlântico, o Pacífico e o Índico constituem oceanos; definições por demonstração (definem por meio de fotografias, ilustrações).

Apesar de essas diferentes definições serem usualmente encontradas nos trabalhos terminológicos, a Norma ISO 1087 prescreve apenas dois tipos, a definição por compreensão que abrange a menção do conceito genérico mais próximo (já definido ou supostamente conhecido) e as características distintivas que delimitam o conceito a ser definido - e a definição por extensão - baseada na enumeração exaustiva dos objetos aos quais um conceito se refere ou nos conceitos específicos que lhe são imediatamente subordinados.

A definição por compreensão é, certamente, a mais adequada aos trabalhos terminológicos, uma vez que ela situa o conceito no âmbito de uma classe e especifica o que o distingue dos outros conceitos situados na mesma classe.

Neste trabalho, vamos expor os problemas relativos à elaboração de definições por compreensão em uma língua de especialidade, a Inteligência Artificial (IA). Essas definições integram os verbetes de um dicionário terminológico que estamos preparando, sobre essa disciplina, dicionário esse que apresenta os seguintes campos em seus verbetes: termo; referências gramaticais; sigla ou forma abreviada; definição; sinônimos (eventualmente); notas (eventualmente). Na busca de uma sistematização que vise a tornar as definições homogêneas e coerentes, encontramos problemas, que aqui apresentamos. Se algumas dessas dificuldades são comuns a todas as línguas de especialidade, algumas são próprias dessa ciência, ainda em construção, e de caráter multidisciplinar.

\section{DEFINIÇÕES DE TERMOS EM IN- TELIGENNCIA ARTIFICIAL}

As definições que estamos elaborando para os termos da Inteligência Artificial baseiamse nos contextos extraídos de um córpus constituído por livros, artigos e anais de congressos sobre essa ciência. São, preferencialmente, definições por compreensão.

Nessas definições, o termo genérico constitui um termo que geralmente não pertence a um domínio particular - conjunto, elemento, estrutura, fase, fórmula, método,parte, procedimento, processo, sistema, entre outros - e seu conceito aproxima-se do significado que essa mesma forma apresenta na língua comum. Segundo Rondeau (1984), esses termos situam-se numa zona intermediária entre a língua comum e as línguas de especialidade.

Desse modo, o termo genérico já introduz o conceito do termo sob análise. Observa-se, assim, que os termos da Inteligência Artificial, ciência interdisciplinar, podem constituir:

um conjunto - analisador de linguagem natural - conjunto de programas que permite ao computador analisar e entender sentenças em língua natural;

um elemento - átomo - elemento indivisível que, ao formar seqüências, representa objetos simples;

uma estrutura - arquitetura de quadro-negro - estrutura que permite a comunicação entre diferentes sistemas especialistas por meio de uma base de dados chamada quadro-negro;

uma fase - aquisição de conhecimento fase importante na construção de sistemas especialistas que consiste na coleta e formalização do conhecimento do especialista e sua transferência para o programa do computador; 
uma fórmula - axioma - fórmula da qual se parte para provar um teorema; um método - dependência conceitual - método de representação do conhecimento usualmente empregado para inferir o significado de sentenças em linguagem natural, independentemente da linguagem na qual as sentenças foram enunciadas;

uma parte - sistema de inferência - parte do sistema especialista que interpreta as regras de conhecimento deduzindo se um programa está dentro dos padrões de programação estabelecidos e sugerindo, quando necessário, as alterações adequadas para melhorar a qualidade da programação;

um processo - compilação - processo que permite a tradução do programa escrito pelo usuário para um programa compreensível e executável pela máquina;

um símbolo - juntor - símbolo lógico que tem a função de ligar sentenças ou fórmulas lógicas; uma subárea - compreensão da linguagem natural - subárea da Inteligência Artificial que tem o objetivo de possibilitar ao computador a manutenção de um diálogo com o usuário por meio de uma língua natural;

uma técnica - tradução por máquina - técnica de Inteligência Artificial que permite ao computador traduzir de uma língua natural para outra.

Assim, embora concordemos com a afirmação de Finatto (1994), segundo a qual, em um trabalho terminológico, "a fixação de diferentes paradigmas definicionais terminológicos é um objetivo a ser alcançado", as diferentes características dos termos que constituem a IA torna difícil uma sistematização, pois alguns enunciados indicam uma finalidade (compilação, juntor, tradução por máquina), uma descrição (aquisição de conhecimento), como vimos, e ainda: algumas características - fuzznet - sistema especialista conexionista que utiliza a teoria dos conjuntos difusos para fazer raciocínio aproximado em SEs baseados em regras. Suas principais características são: número variável de antecedentes e consequientes das regras; exclusão de informações da base de conhecimentos; negação de expressões nos antecedentes das regras;

rubicon - sistema especialista conexionista utilizado para a implementação de sistemas especialistas baseados em regras. Suas características são: número arbitrário de antecedentes e conseqüentes em qualquer regra; inclusão e remoção de elementos na memória de trabalho; manipulação de expressões negativas nos antecedentes e conseqüentes das regras;

um exemplo - anáfora - elemento de coesão textual que estabelece referência por retomada. Por exemplo, em "Tenho um gato. Ele é siamês", "ele" exerce função de anáfora;

a forma de uma regra - produção - regra que armazena informação dos sistemas de produção e apresenta a forma: se alguma premissa for verdadeira, então alguma conclusão;

e, não raro, uma constituição - argumento - um dos componentes das estruturas do Prolog, utilizado para nomear individualmente as partes de um objeto composto. Pode ser constituído por números, constantes, variáveis e outras estruturas;

arquitetura do sistema especialista - estrutura do sistema especialista composta de três elementos básicos: base de conhecimento, motor de inferência e banco de dados;

teoria com defaults - fórmula constituída por um conjunto de defaults e um conjunto de fórmulas de primeira ordem.

$\mathrm{Na}$ apresentação das características específicas de alguns termos, fazemos, com fre- 
qüência, referência a outros termos da Inteligência Artificial, que também devem ser definidos:

árvore binária - árvore cujos nós apresentam, cada um, apenas dois filhos;

nó - num grafo, ponto que representa objetos ou estados;

cláusula de Horn - cláusula que comporta, no máximo, um literal positivo;

literal - fórmula atômica que pode ser positiva ou negativa.

Seguindo Felber (1987), em nosso trabalho as características análogas dos conceitos são sempre expressas por estruturas sintáticas e lexicais idênticas:

busca para frente - busca que, na resolução de um problema, parte de um estado inicial para um estado objetivo;

busca para trás - busca que, na resolução de um problema, parte de um estado objetivo para um estado inicial.

A natureza dos termos da Inteligência Artificial leva-nos também a adotar, no entanto, alguns princípios que devem ser evitados na prática terminográfica.

O enunciado definitório não deve comportar, lembram-nos de Bessé (1990) e Felber (op. cit.), o termo que está sendo definido. A infração a essa regra, no entanto, torna-se necessária em alguns casos, como na definição dos sintagmas nominais, muito freqüentes em todas as línguas de especialidade.

$\mathrm{Na}$ definição desses sintagmas, o termo genérico é geralmente constituído pelo termo determinado do sintagma, que também constitui um termo da terminologia da Inteligência Artificial, e, portanto, deve igualmente ser definido: busca bidirecional - busca que utiliza simultaneamente dois caminhos para a resolução de um problema: do estado inicial para o estado objetivo e do estado objetivo para o estado inicial, até que os dois caminhos se unam em algum lugar;

busca - estratégia de resolução de problemas que parte de um estado inicial para um estado objetivo, utilizada quando não há uma àbordagem mais direta disponível;

representação declarativa - representação que enfatiza os aspectos estáticos do conhecimento, isto é, fatos sobre objetos, situações e suas relações e fatos gerais sobre o mundo;

representação - em psicologia cognitivà; réferência aos diversos tipos de apreensão de um objeto.

Nem todas as definições podem ser iniciadas por um termo genérico. A referência a um subdomínio torna-se necessária, sobretudo, quando o termo reflete o caráter interdisciplinar da Inteligência Artificial:

algoritmo de unificação - em lógica de predicados, algoritmo utilizado para comparar dois literais, com a finalidade de determinar se existe um conjunto de substituições que os torne idênticos;

semântica - em lingüística, área que faz a interpretação do significado de palavras e enunciados.

A referência revela, também, que o termo reflete uma fase, um elemento, um fenômeno de um processo, uma operação, uma teoria, etc.: ciclo - num grafo, caminho em que um dado nó aparece mais de uma vez; conjunto nebuloso - na teoria dos conjuntos, subconjunto constituído de dados imprecisos lo- 
calizados entre dois extremos arbitrariamente estabelecidos;

estado inicial - num espaço de estados, estado que representa a situação inicial referente à resolução de um problema;

representação de problema - no processo de resolução de problemas, fase em que os vários estados relativos à solução de um problema são simbolizados;

ramo - numa árvore, segmentos de reta que ligam dois nós e representam as operações que transformam um estado em outro.

Assinala também de Bessé (op. cit.) que a definição terminológica, sem ser enciclopédica, parte, tanto quanto a definição enciclopédica, de elementos extralinguísticos. No entanto, diferentemente da definição enciclopédica, a definição terminológica visa apenas a dar as informações que permitem distinguir um conceito no interior de um sistema conceitual.

O dicionário terminológico da Inteligência Artificial que estamos elaborando apresenta notas enciclopédicas em seus verbetes. Apesar disso, parece-nos justificável que algumas definições apresentem um cunho enciclopédico, na medida em que a informação enciclopédica facilite a delimitação de um conceito. Assim, a definição que propusemos para o termo teste de Turing é, sem dúvida, de natureza enciclopédica. Informa sobre o autor do teste, a data em que ele foi formulado e revela como ele deve ser executado:

teste de Turing - teste proposto por Alan Turing, em 1950, para determinar se um computador pode pensar como um ser humano. Para sua execução, são necessárias duas pessoas e a máquina a ser avaliada. Uma das pessoas exercerá o papel do interrogador, que ficará em uma sala distinta da ocupada pelo computador e pela outra pessoa. O interrogador formulará ques- tões para a máquina e a pessoa, sem saber quem é uma ou outra.

De maneira análoga, pareceu-nos necessário introduzir elementos de natureza enciclopédica na definição do termo Inteligência Artificial: subárea das Ciências da Computação, que se constituiu por volta de 1956 , cujo propósito consiste em fazer o computador raciocinar, aprender e agir como um ser humano.

A definição de um conceito deve ser concisa (cf. Felber, op. cit.) e comportar, preferencialmente, uma única frase. Nem sempre, porém, este princípio pôde ser respeitado em nosso trabalho:

análise intermediária - estratégia de resolução de problemas que se concentra na busca de diferenças entre o estado atual e o estado meta. Torna possível resolver primeiro as principais partes de um problema e em seguida voltar para resolver os pequenos problemas restantes;

regra de inferência - regra que utiliza raciocínio dedutivo para a solução de problemas. As principais regras de inferência são chamadas de "modus ponens" e "modus tollens".

\section{CONSIDERAÇÕES FINAIS}

Apresentamos, assim, alguns problemas com que temos nos deparado ao elaborarmos definições por compreensão da terminologia da Inteligência Artificial. Busca do termo genérico e delimitação do conceito em relação a outros conceitos por meio de características que o especifiquem não são, certamente, tarefas simples, o que nos permite concluir, com Desmet (1990), que entre a prática do enunciado definitório e a aproximação do modelo teórico há sempre um caminho, por vezes tortuoso, a ser percorrido. 


\section{BIBLIOGRAFIA}

DE BESSÉ, B. (1990) La définition terminologique. In: Centre d'etudes du lexique. Paris, Larousse, p. 254-255.

DESMET, I. (1990) Questões de semântica em terminologia (A problemática da definição terminológica). Terminologias, vol.2, p. 16.

FELBER, H. (1987) Manuel de terminologie. Paris, UNESCO/Infoterm, p. 139-140.

FERREIRA, A. B.de H. (1986) Novo dicionário da língua portuguesa. $2^{\mathrm{a}}$ ed. Rio de Janeiro, Nova Fronteira.
FINATTO, M. J. B. (1994) Caracterização de paradigmas definicionais terminológicos. In: Actas do IV Simpósio Iberoamericano de Terminologia, p. 59.

Norme Internationale ISO I 087. 1990.

RONDEAU, G. (1984) Introduction à la terminologie. Québec, Gaetan Morin, p. 24.

SAGER, J.C. (1990) A practical course in terminological processing. Amsterdam-Philadelphia, Johns Benjamim Publishing Company, p. 42-4. 